\title{
The Role of Endoscopic Treatment in Acute Lithiasis Cholangitis (Retrospective Study of 186 Cases)
}

\author{
R. Berraida*, I. Elkoti, A. Benhamdane, R. Laaroussi, H. Iroughman, Y. Touibi, I. Redouan, M. Osmane Guelleh, T. Addajou, S. \\ Mrabti, F. Rouibae, A. Benkirane, H. Seddik \\ Department of Gastroenterology II, Mohammed V. Rabat Military Hospital, Morocco
}

Correspondence to: R. Berraida, Department of Gastroenterology II, Mohammed V. Rabat Military Hospital, Morocco Received date: January 03, 2022; Accepted date: January 14, 2022; Published date: January 21, 2022

Citation: Berraida R, Elkoti I, Benhamdane A, et al. (2022) The Role of Endoscopic Treatment in Acute Lithiasis Cholangitis (Retrospective Study of 186 Cases). J Med Res Surg 3(1): pp. 1-3. doi: 10.52916/jmrs224066

Copyright: (C2022 Berraida R, et al. This is an open-access article distributed under the terms of the Creative Commons Attribution License; which permits unrestricted use; distribution and reproduction in any medium; provided the original author and source are credited.

\section{ABSTRACT}

The acute cholangitis is a bacterial infection of the bile ducts due to an acute obstacle. It is a therapeutic emergency that can be life threatening. The purpose of this study is to evaluate the results of endoscopic drainage in patients with acute giocholitis.

\section{Keywords:}

Endoscopic sphincterotomy, ERCP, Acute cholangitis

\section{Introduction}

Acute cholangitis is inflammation of the bile ducts, and bile. Usually, it is due to an infection of the bile by bacteria from the digestive tract following a sudden obstruction of the bile ducts [1].

Classic symptoms are represented by Charcot's triad (pain, fever, jaundice).

Imaging, in particular cholangio-MRI (Bili MRI) [2-3] is a decisive adjunct for the aetiological diagnosis and the therapeutic strategy.

Chronic cholangitis is a therapeutic emergency due to the possible progression to life-threatening septic shock.

The aim of our work was to assess the results of emergency endoscopic drainage of cholelithiasis of cholelithiasis in terms of stone removal and improvement in morbidity and mortality.

\section{Material and Methods}

It is a retrospective study that lead at the Gastro-enterology Department of the Military Hospital of Rabat from April 2002 to December 2016, including 186 patients benefit of a ERCP for acute cholangitis. We analyzed the epidemiological data of the patients, the results of ERCP, and morbidity and mortality after Endoscopic Biliary Sphincterotomy (EBS).

In our study, the indication for ERCP was acute cholelithiasis in 186 patients, which represents $6.3 \%$ of all ERCPs performed.

The average age was $62+/-13.48$ years, with extremes ranging from 21 to 96 years. Among the 186 cases of acute cholelithiasis, there was a slight female predominance. $\mathrm{N}=98$ women with a percentage of $52.6 \%$ and $n=88$ men for a percentage of $47.3 \%$ (Figure 1).

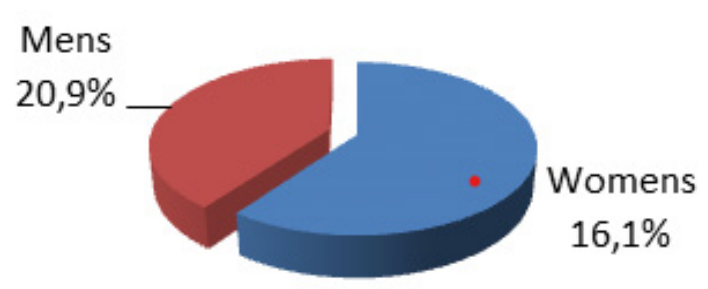

Figure 1: Distribution of patients by sex.
The mean diameter of the VBP was $14.93 \mathrm{~mm} \pm 4.7$. Clearance of BVP after a single catheterization was achieved in $60.5 \%$. Recovery of the patient was noted in $13.5 \%$ of cases with failure of catheterization in 7 patients $6.58 \%$ due to a major duodenal change.

Different therapeutic actions were performed during the ERCP: (Figure 2).

An endoscopic biliary sphincterotomy was performed in all patients, i.e. $100 \%$.

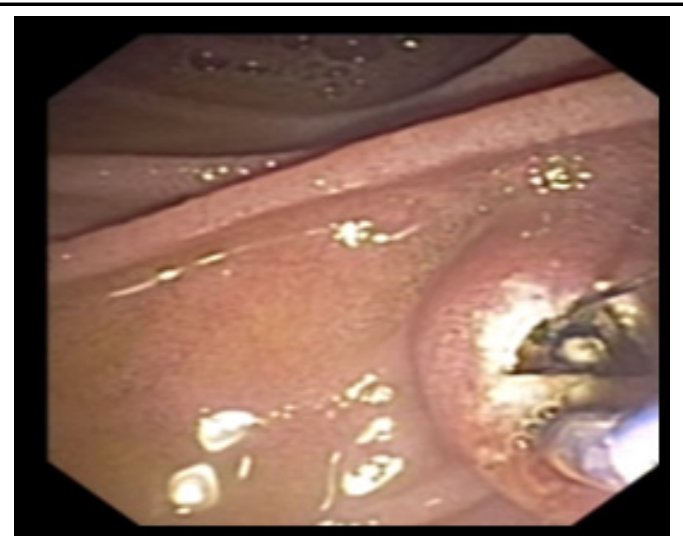

Figure 2: Endoscopic view of an endoscopic biliary sphincterotomy in a patient admitted for acute gallstones.

Extraction of one or more stones of variable size was noted in 85 cases, i.e. $80.9 \%$ (Figure 3 ).

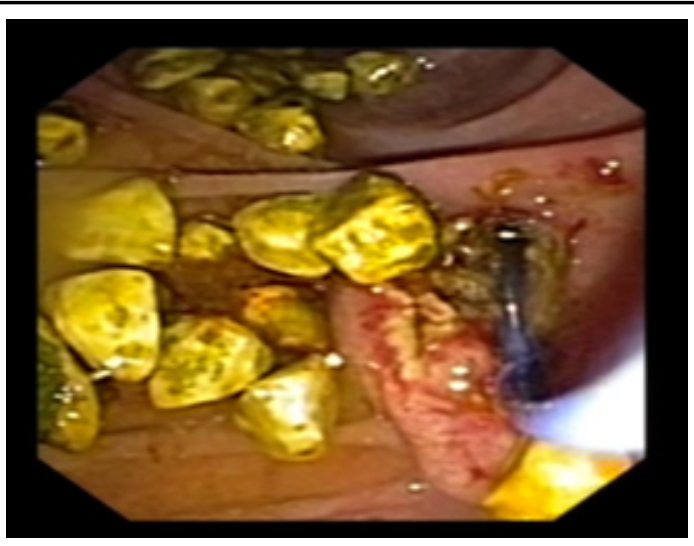

Figure 3: Endoscopic view showing the extraction of several stones from the PBV after endoscopic biliary sphincterotomy. 
A nasolabiliary drain was placed in 39 cases, $21.1 \%$ (Figure 4).

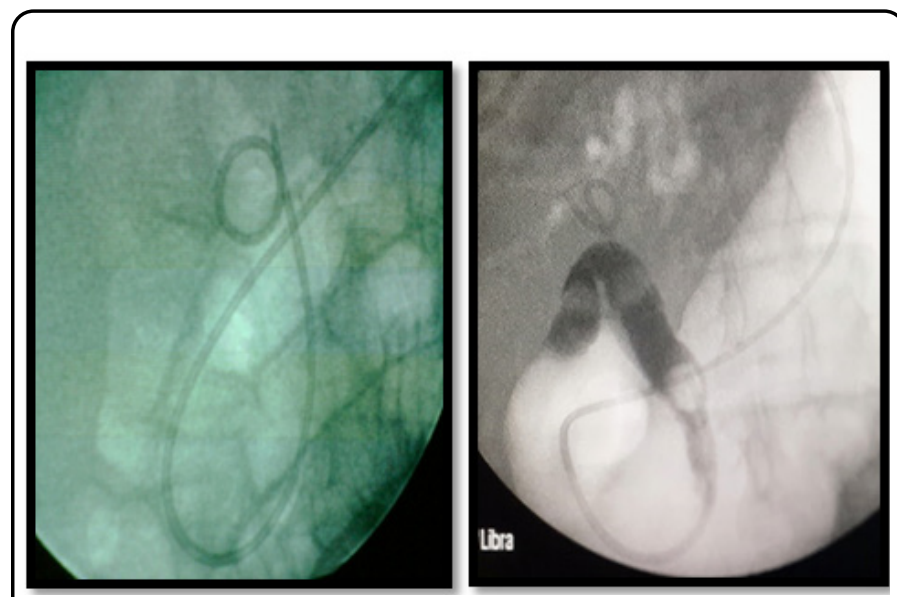

Figure 4: Fluoroscopic appearance showing a nasolabial drain in the PBV.

A sphincteroplasty was performed in 8 patients who presented with large stones, i.e. $4.3 \%$ (Figure 5).
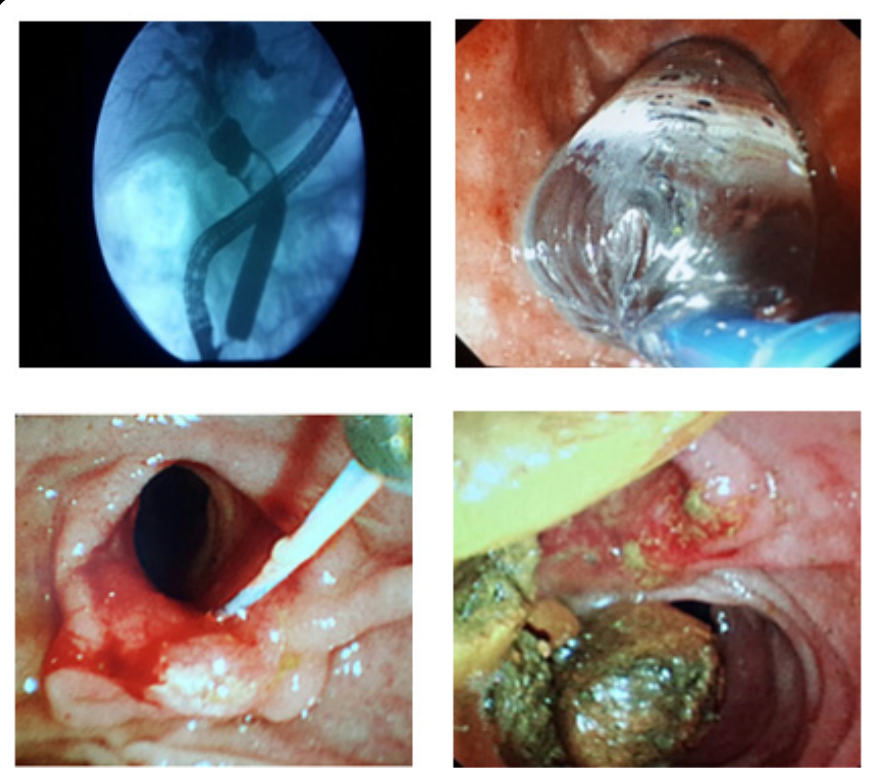

Figure 5: Sphincteroplasty; A): Radiological view dilation balloon is inserted and inflated; B): Endoscopic view, the balloon is positioned astride the sphincter of Oddi; C): stone extraction after sphincteroplasty; D): Endoscopic appearance of the papillae post macro dilation.

The retrograde opacification control which made it possible to conclude that the BPV was completely evacuated was obtained in 100 patients ( $95.2 \%$ of cases) (Figure 6$)$.

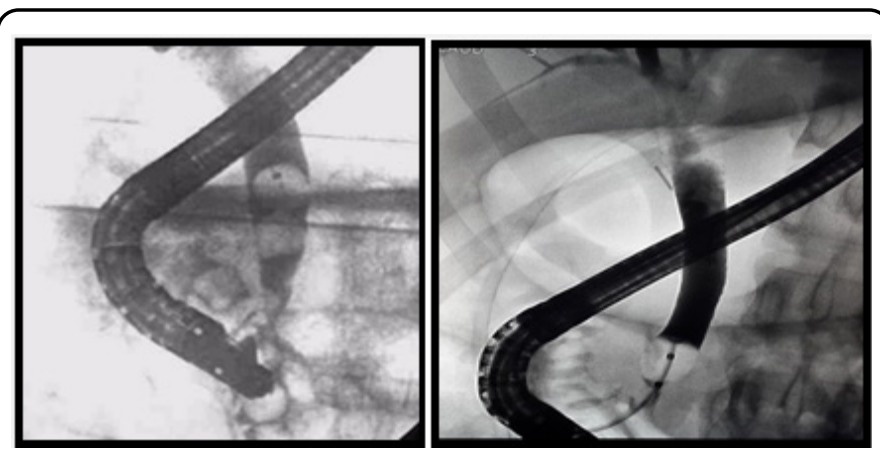

Figure 6: Fluoroscopic appearance of the emptiness of the main bile duct after CPRE-SBE.
The overall success rate after recovery of the patient and / or carrying out additional maneuvers was $80.5 \%$

Early complications after ERCP with endoscopic sphincterotomy were noted in 13 patients $(6.4 \%)$ :

- $\quad$ Eight patients (4.3\%) presented minimal gastrointestinal bleeding due to bleeding from the edges of the sphincterotomy, hemostasis was obtained by endoscopic treatment (pneumatic compression using an extraction balloon).

- Two patients (1.1\%) presented with acute post-ERCP pancreatitis.

- $\quad$ One case of bulbar perforation, ie $0.53 \%$, requiring surgical management.

\section{Discussion}

Angiocholitis is a bacterial infection of the main bile duct or intrahepatic bile ducts causing systemic signs [2], this infection almost always complicates an obstruction to the outflow of bile. In more than $90 \%$ of cases, this obstacle is of lithiasic origin. Chronchitis manifests itself in its typical form by the Charcot triad associating: a pain like hepatic colic, a high fever of sudden onset, and so delayed cholestatic jaundice. [3], severe forms from the outset are frequent and result in a picture of sepsis [4].

The frequency of cholangitis is linked to that of biliary pathology because it is the major complication of choledocholithiasis. In our series, the indication for ERCP was acute cholelithiasis in $6.3 \%$ of cases.

Chronic cholangitis can occur at any age but more frequently between 50 and 80 years of age, exceptionally before 20 years [5-6].

The distribution of our patients by age shows the average age of 62 years, with extreme ages of 21 and 96 years, which is close to the figures reported by most authors (Table 1).

Table 1: The age of patients with cholelithiasis acute according to different series.

\begin{tabular}{|l|l|}
\hline Auteurs & Age moyen \\
\hline HOUDART and collaborators & 66,3 \\
\hline MOUMEN & 48 \\
\hline JAYS & 67,7 \\
\hline DUBOISF & 60 \\
\hline FARIH & 57 \\
\hline HUGUIER & 56 \\
\hline ABARRAH. K & 53 \\
\hline Our series & 62 \\
\hline
\end{tabular}

The diagnosis of Acute Cholelithiasis (AAL) is based on clinical, biological, and morphological arguments. The role of imaging in the diagnosis and management of patients with suspected cholangitis is essential [1]. Ultrasound remains the first-line examination in patients with suspected cholangitis of lithiasis. Computed tomography without injection, with acquisitions in thin sections, is more sensitive than ultrasound to detect low bile duct stones. However, it remains less effective than cholangioMRI, which, together with ultrasound endoscopy, is the most sensitive technique for detecting low bile duct stones [7] 
Therapeutically, all patients with acute cholelithiasis regardless of the severity of the cholangitis, should receive antibiotic therapy.

Endoscopic biliary drainage is the most effective treatment for biliary decompression in acute cholelithiasis. ERCP is associated with significantly lower morbidity and mortality than surgical decompression. In a randomized controlled trial comparing surgical decompression versus endoscopic decompression in patients with ALA, the morbidity and mortality rate was significantly higher in the surgically treated group [8-9].

The purpose of an endoscopic sphincterotomy is to allow stone extraction and decompression of the bile ducts. In favorable cases and especially in cases of small stones or bile sludge, the stones are evacuated spontaneously under the effect of the bile flow (58.5\% for Safrany et al. [10]. But most often, the the use of extractors, in particular the basket catheter (Dormia catheter) or balloon catheter is necessary (32\% for the same author).

In severe cholangitis with haemostatic disturbances, simple temporary endoscopic biliary drainage without SBE is recommended [11]. This biliary drainage can be done through the placement of a DNB or a plastic biliary prosthesis. The two drainage modalities have similar technical and clinical success rates [9].

The early complications of ERCP are those occurring within 30 days of the procedure. Some of these complications are not specific to the technique but linked to the site. They are observed in $4 \%$ of cases and lead to the death of the patient in $3 / 4$ of cases, ie $3 \%$ of patients [12].

The main complications of biliary catheterization with SBE are represented in order of frequency by: BP, haemorrhage, biliary infection and perforation [13].

The landmark study by Freeman et al. [14] involving 2347 patients showed that post-sphincterotomy bleeding is significantly higher in patients with acute cholangitis even in the absence of coagulopathy.

In our series, among the 6 bleeds concomitant with SBE, i.e $4.3 \%$, none corresponded to a true hemorrhage. It was minimal bleeding from the banks which was controlled by pneumatic compression.

\section{Conclusion}

Endoscopic sphincterotomy is a safe and effective measure for the management of choledocholithiasis and acute cholangitis. Its results are satisfactory, with morbidity and mortality less than surgical treatment.

\section{References}

1. BP Gallix, S Aufort, MA Pierredon, et al. (2006) Continuing medical education update on ... Chronic cholitis: how to recognize it? What behavior to take? French edition of radiology, paris 2006.

2. Karel J. van Erpecum (2006) Complications of bile-duct stones: Acute cholangitis and pancreatitis, Best Pract Res Clin Gastroenterol 20(6): pp. 1139-1152.

3. Anciaux Ml, Pelletier G, Attali P, et al. (1986) Prospective study of clinical and biochemical features of symptomatic choledocolithiasis. Dig Dis Sci 31(5): pp. 449-453.

4. Lee DHW, Chan ACW, Lam YH, et al. (2002) Biliary decompression by nasobiliary catheter or biliary stent in acute suppurative cholangitis: a prospective randomized trial. Gastrointest Endosc 56(3): pp. 361-365.

5. K Brakel, J S Laméris, HG Nijs, et al. (1990) Predicting gallstone composition with $\mathrm{CT}$ : in vivo and in vitro analysis. Radiology 174(2): pp. 337-341.

6. Cocroli-Bosc FX, Ferrari P, Paolini O (2000) Influence of age and hormonal variations on vesicular motricity in subjects with and without lithiasis. J F Path Dig 2000: pp. 18-22.

7. Hakansson K, Ekberg O, Hakansson HO, et al. (2002) MR Characteristics of acute cholangitis. Acta Radiol 43(2): pp. 175179.

8. Lai EC, Mok FP, Tan ES, et al. (1992) Endoscopic biliary drainage for severe acute cholangitis. N Engl J Med 326(24): pp. 1582-1586.

9. Ramchandani M, Pal P, Reddy DN (2017) Endoscopic management of acute cholangitis as a result of common bileduct stones. Dig Endosc 29(S2): pp. 78-87.

10. Safrany L (1978) Endoscopy treatment of biliary-tract diseases. An international Lancet study 2(8097): pp. 983-985.

11. Sawas T, Arwani N, Al Halabi S, et al. (2017) Sphincterotomy with endoscopic biliary drainage for severe acute cholangitis: a meta-analysis. Endosc Int Open 5(2): pp. 103-109

12. Martin L. Freeman, Douglas B. Nelson, Stuart Sherman, et al. (1996) Complications of endoscopic biliary sphincterotomy. N England J Med 335: pp. 909-918.

13. Liguory C, Lefebvre JF, De Paulo Ga, et al. (2001) Endoscopic treatment of lithiasis of the main bile duct. Encycl. Med Chir (Elsevier), Surgical Techniques, Digestive System. pp. 40-955.

14. Freeman ML (1997) Complications of endoscopy biliary sphincterotomy: a review. Endoscopy 29(4): pp. 288-297. 